\title{
CITATION
}

Bayer, J. B., Lewis, N. A., \& Stahl, J. L. (2020). Who Comes to Mind? Dynamic Construction of Social Networks. Current Directions in Psychological Science, 29, 279-288.

Published Version available at: https://doi.org/ I 0.I I77/096372 | 4209 I 5866

\section{Who Comes to Mind? Dynamic Construction of Social Networks}

\author{
Joseph B. Bayer ${ }^{1,2}$, Neil A. Lewis Jr. ${ }^{3,4}$, and Jonathan L. Stahl ${ }^{5}$ \\ ' School of Communication, The Ohio State University \\ ${ }^{2}$ Translational Data Analytics Institute, The Ohio State University \\ ${ }^{3}$ Department of Communication, Cornell University \\ ${ }^{4}$ Department of Medicine, Weill Cornell Medical College \\ ${ }^{5}$ Department of Psychology, The Ohio State University
}

\begin{abstract}
Much remains unknown about moment-to-moment social-network cognition - that is, who comes to mind as we go about our day-to-day lives. Responding to this void, we describe the real-time construction of cognitive social networks. First, we outline the types of relational structures that comprise momentary networks, distinguishing the roles of personal relationships, social groups, and mental sets. Second, we discuss the cognitive mechanisms that determine which individuals are activated - and which are neglected - through a dynamic process. Looking forward, we contend that these overlooked mechanisms need to be considered in light of emerging network technologies. Finally, we chart the next steps for understanding social-network cognition across real-world contexts, along with the built-in implications for social resources and intergroup disparities.
\end{abstract}

\section{Keywords}

social resources, social-network cognition, cognitive social structures, online networks, social media, communication technologies

We are more likely to achieve our goals when drawing on the talents, lessons, and viewpoints of people we know. Who we reach out to - or at least think of - depends on our knowledge of elaborate social networks, including favored friends, rumored rivals, and all of the connections among them. Sometimes these perceptions of our social worlds are accurate, although often they are far from precise. As in other facets of human psychology, who comes to mind is not random: We see customized versions of our networks that are filtered through cognitive biases and heuristics (Brashears \& Quintane, 2015). 
Despite multiple bodies of research exploring the psychology of social networks (e.g., Burt, Kilduff, \& Tasselli, 20I3; Mattan, Kubota, \& Cloutier, 2017), how other people are arranged in our minds and how they affect social cognition in daily life is not well understood. Although substantial research has studied long-term social-network memory, we are just beginning to grasp how such information is retrieved and recoded in real time (Smith, Brands, Brashears, \& Kleinbaum, 2020). The goal of this article is to elucidate the dynamic mechanisms of everyday social-network cognition and to begin mapping those mechanisms onto downstream outcomes.

\section{Social-Network Cognition}

Social-network cognition refers to the process or processes by which humans encode, represent, retrieve, and perceive the links between individuals and groups (Brands, 20I3; Casciaro et al., 20I5). Hence, the cross-disciplinary literature on social-network cognition focuses on how people mentally represent not just their discrete relationships or groups but also the real or perceived links among people in an interpersonal web (Brashears, 20 I 3; Brashears \& Quintane, 2015; Burt, Jannotta, \& Mahoney, 1998; Krackhardt, 1987).

Early research on cognitive social structures found that humans are not very effective at remembering facts about our social relationships and interaction patterns (e.g., Bernard \& Killworth, 1977). This ability (or inability) to remember and recall network information is not uniform. Instead, the ability to recall depends on the network information at hand and individual traits (Brashears, Hoagland, \& Quintane, 2016). In particular, we are better at remembering networks that have hierarchical relationships (Zitek \& Tiedens, 2012) or network information that is linked to familiar categories such as "families" (Brashears, 20I3). Other individual-level factors can also affect network perception; as one example, people with high need for closure are more likely to assume that mutual friends know each other, especially if they were from the same racial group (Flynn, Reagans, \& Guillory, 20l0). Thus, we engage a clear "small-world” bias in which friends are separated into well-defined buckets - when real social networks are much more complicated (Kilduff, Crossland, Tsai, \& Krackhardt, 2008). People in the network that fall outside of clear-cut social structures are likely to be misremembered or misrepresented (for reviews, see Brands, 20I3; Brashears \& Quintane, 20I5).

Altogether, the complexity of social networks leads individuals to rely heavily on mental heuristics. These heuristics and their associated biases have important consequences for social behavior. To the extent that biases obscure memories, individuals may be unable to fully leverage their social resources (Brands, 2013). Much less is known, however, about how particular parts of our networks become salient - or how cognitive social networks influence behavior across the diverse contexts seen in everyday life.

\section{Who Comes to Mind?}

What determines who comes to mind at a given moment? Although social networks have concrete and measurable properties, emerging work reveals that how those networks are represented in the mind varies across situations (Smith, Menon, \& Thompson, 2012). Specifically, prior work has delineated three types of mental networks that occur through this dynamic construction process: potential, activated, and mobilized networks (Menon \& Smith, 2014; Smith et al., 2012). Potential networks contain the complete collection of people who are known to an individual. A subset of those people exists in activated networks in which they remain salient in 
short-term memory so we can easily draw on them to satisfy current needs. Yet how a cognitive social network is winnowed from potential to activated to mobilized - and how activation matters independently of mobilization — remains nebulous.

Here, we consider the broader influence of activated networks during daily life. Because our personal networks are partly a reflection of ourselves (Menon \& Smith, 20I4; Walker \& Lynn, 20I3), the people on our minds provide a lens through which we process the world around us (Oyserman \& Lewis, 2017). In fact, how we construct our identities is based in part on how we see — and communicate about - our social networks (Anthony \& McCabe, 20I5). As a consequence, the dynamic construction of identity via our activated social networks can motivate us to enact and change our behaviors (Oyserman et al., 20l7).

An activated network can be divided into two dimensions: (a) the exclusive list of people who are salient at a given moment (nodes) and (b) the perceived connections among those people (edges). These dimensions can be characterized by two questions: "Who comes to mind?" and "How are they connected?" Together, the two dimensions compose the network structure, which can be described in terms of measures such as size (number of nodes), density (interconnectedness of nodes), and communities (number of clusters within the overall network). As depicted in Figure I, an activated network is made up of personal relationships, social groups (individuals who are perceived to know one another), or mental sets (individuals who may not know each other but share some characteristic in memory). Next, we explicate the factors that shape these momentary social networks.

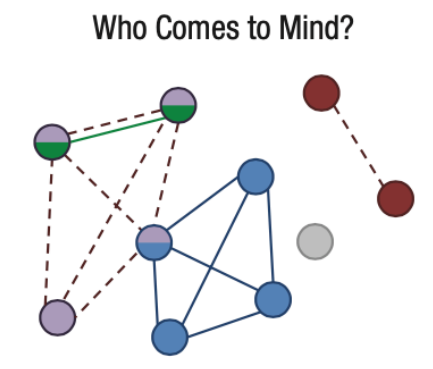

Personal Relationships

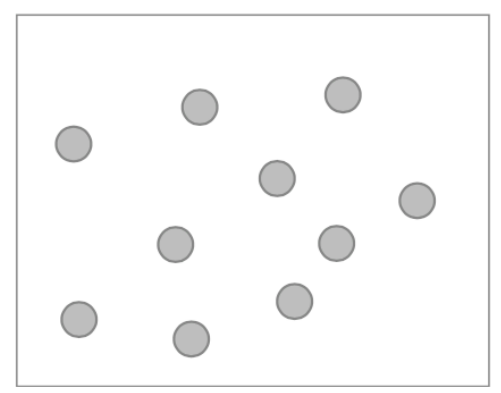

Social Groups

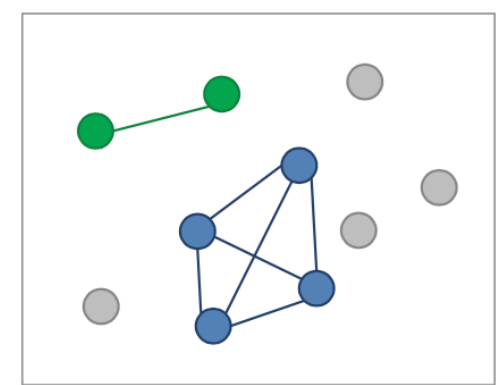

Mental Sets

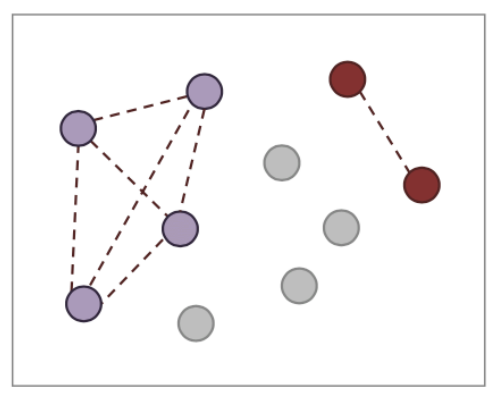

FIGURE I

Figure I displays three types of relational structures that comprise activated networks. First, the network can be viewed as the complete collection of personal relationships (nodes) who are salient (Left). Next, the network can be described in terms of the connections (edges) between those individuals as social groups (Middle) or mental sets (Right). Groups (shown in green and blue) represent perceptions of who knows who (e.g., work colleagues, trivia teammates). Sets (shown in purple and maroon) denote a combination of people who are linked in memory (e.g., best friends, jazz fans), whether or not they know one another. Together, relationships, groups, and sets constitute a momentary network - i.e., who comes to mind (Top). 


\section{Goal activation}

Recent studies have highlighted the significance of active goals (Shea \& Fitzsimons, 20I6) and situational factors (Small \& Sukhu, 2016) in influencing, directly or indirectly, who is likely to appear in an activated network (cf. Westaby, Pfaff, \& Redding, 2014). A number of factors have been shown to call larger or smaller networks to mind, such as positive as opposed to negative affect for mood regulation (Shea, Menon, Smith, \& Emich, 2015) and perceived status for job pursuit (Smith et al., 20I2). In this way, the networks that come to mind throughout everyday life are constructed as a function of the deliberate goals being pursued at that time (see Fig. 2, blue circles). For example, identifying as a "networker" shifts what interpersonal goals individuals prioritize (Raj, Fast, \& Fisher, 2017). Thus, some parts of a cognitive network will be more salient because of expectations or goals for future social interaction, such as an individual yearning for a message to arrive from a romantic partner or imagining the audience of an upcoming Instagram story (Honeycutt, Vickery, \& Hatcher, 2015; Litt, 20I2). As individuals shift their goals on a moment-to-moment basis, however, the activated network changes: When Hakeem is working on his research, his collaboration network becomes salient; when he wants to check out a new restaurant, his foodie friends come to mind.

\section{Habitual activation}

Sometimes people are thought of because of our goals, but other times they come to mind because of habits formed from repeated engagement (Bayer, Campbell, \& Ling, 2016; Small, 2017; see also Wood, 2017). By focusing primarily on decision-making, previous work on socialnetwork cognition has often overlooked the role of automatic cognition. By contrast, socialnetwork habits reflect a version of automaticity in which some people are regularly thought of unconsciously (Fitzsimons \& Bargh, 2003). As certain network facets are activated regularly in particular contexts, these parts of the net- work become salient when triggered by contextual cues. A diverse range of states (e.g., lonely), locations (e.g., office), or channels (e.g., Snapchat) can act as cues for network habits. Over time, habitual activation may engender a chronic social network in which certain relationships, groups, and sets become more widely accessible because of their associations with a generalizable set of cues (see Fig. 2, red circles).

\section{Structural activation}

Adopting a dynamic-construction view also requires examining how the structure of the cognitive network matters on its own. Most significantly, the process of spreading activation (see Wentura \& Rothermund, 2014) may activate interrelated parts of the cognitive social network. Previous research shows that the activation of a single node may influence which node is activated next (Marin, 2004). More broadly, groups and sets may come to mind in the context of individual nodes via wider-spreading activation (see Fig. 2, yellow circles). The salience of a childhood best friend can influence the cognitive accessibility of other relationships (e.g., mutual friends), groups (e.g., college classmates), or sets (e.g., best friends). The converse is true as well; thinking of a college crew can bring to mind a former professor. Additionally, the precise structure of an activated network may stem or prompt activation of further nodes; denser communities are more likely to result in more extensive activation of the potential network. In this way, the activation process can be bidirectional; structural aspects of the activated network may facilitate 
the retrieval of certain people and vice versa (see also Smith et al., 2020).

\section{FIGURE 2}

Figure 2 illustrates how social networks are dynamically constructed through multiple sources of activation. In this example, a romantic partner $(A)$ and three best friends $(B, C, D)$ are salient due to habitually thinking of them in daily life (red). In parallel, three work friends (E, F, G) are also salient due to their relevance to an active goal being pursued, such as seeking job advice (blue). Third, another friend $(X)$ is salient due to a recent chance encounter, such as scrolling down a social media stream (orange). Finally, the goal and incidental activations spur more relationships $(\mathrm{H}, \mathrm{I}, \mathrm{J}, \mathrm{Y}, \mathrm{Z})$ to become salient due to spreading activation (yellow). As a whole, the four activation paths merge to construct a momentary network, which then influences subsequent goal, habitual, and structural activations.

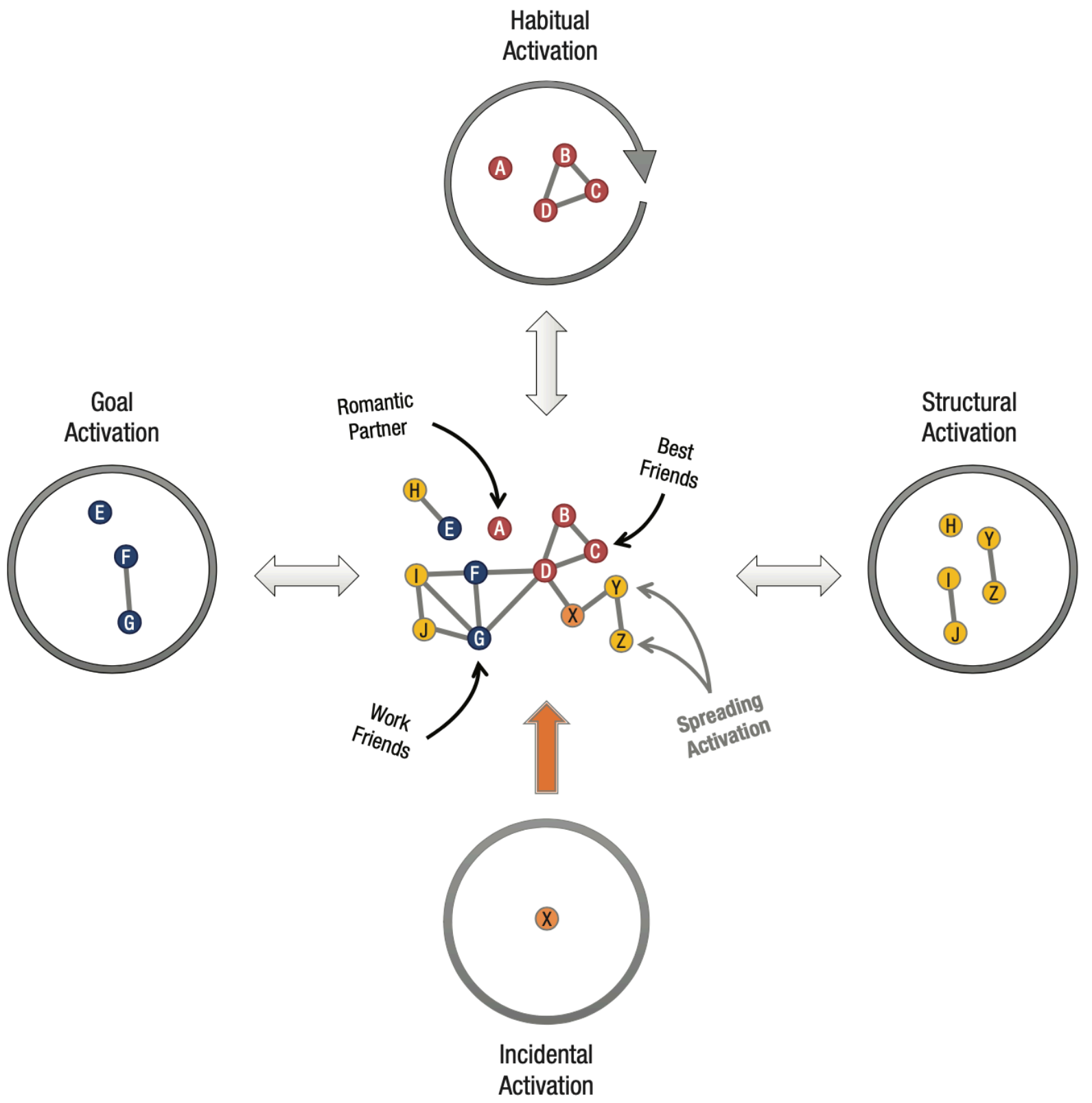




\section{Incidental activation}

Moving beyond a mobilization-specific framework necessitates greater consideration of the inadvertent factors that can shape everyday activation (e.g., seeing a smartphone notification, viewing a distant acquaintance recommended on Facebook). Even when people are pursuing direct mobilization goals, a surprisingly large share of network interactions emerge from incidental decision-making (Small \& Sukhu, 20I6). Thus, the dynamic construction of social networks likely involves might be viewed as cognitive noise on the surface, their prevalence has the potential to shape the overall structure in unexpected ways (see Fig. 2, orange circles).

\section{Implications}

As illustrated in Figure 2, the four types of activation contribute to a composite social network (in the center of the figure) - who comes to mind at a given moment. This momentary network, in turn, influences subsequent goal (blue circles), habitual (red circles), and structural (yellow circles) activations through a perceptual process. Going forward, the direct and indirect relationships among the sources of activation should be investigated in naturalistic contexts. Notably, network habits warrant special attention because intimate relationships should have the most intricate memory schemata (see Sutcliffe, Dunbar, Binder, \& Arrow, 20I2) and thus the most persistent impact on activation patterns. Overall, clarifying how in vivo activated networks are generated and how different sources of activation are combined is critical to untangling realworld effects.

In addition, a dynamic-construction perspective calls for a better understanding of when certain types of relational structures (relationships vs. groups vs. sets) manifest in the mind, along with how the combination of people matters in aggregate. Because multiple structures can be salient simultaneously, studies should test how the constituent parts of activated networks have interactive effects. For example, density has been linked to perceptions of entitativity - how much a group is seen as a coherent unit (Igarashi \& Kashima, 20II) - so researchers must account for the parallel processing of network structure and group cognition. In doing so, studies should strive to tease apart the effects of scope (Who is activated?) from structure (Who is connected?), which have often been confounded in previous work.

By disentangling the distinct processes, psychological scientists can better illuminate the implications beyond mobilization. Researchers are just starting to demarcate the full spectrum of mental activations and assemblages that compose in vivo social networks, and we next discuss why these mechanisms represent a promising direction to pursue.

\section{Network technologies}

Explicating the precise mechanisms of social-network activation is particularly important in light of emerging mobile and online network technologies. Emergent media have the potential to alter and augment activation itself, thereby influencing which relationships are reinforced by default. For example, social platforms can "autofill" interaction choices on the basis of contextual factors (e.g., time, location, channel) or help individuals schedule interactions with lower coordination effort. Platforms may help individuals automate parts of their relationship 
maintenance, such as sending situational reminders to interact with overlooked ties (Kobayashi, Boase, Suzuki, \& Suzuki, 2015) rather than defaulting to habitual ties. For these reasons, new technologies may or may not attenuate some of the cognitive, temporal, and motivational hurdles cited as hindrances to relational maintenance (Dunbar, 2018).

Following advances in relationship-goal research (e.g., Fitzsimons \& Finkel, 2018; Orahek \& Forest, 2016), emerging technologies may also bolster people's ability to reflect on social-network goals and form new goals for (or with) their relationships. For instance, social platforms may support goal coordination or help users visualize the decaying parts of their networks to protect long-term connections. Indeed, research suggests that the advantages of being a network "broker" are linked to acute social-network perception (Kilduff \& Lee, 2020). Because people are better at remembering networks via category heuristics, social media may assist individuals in organizing and navigating their various ties, groups, and sets. Altogether, cognitive network technologies have the potential to influence how people allocate, or curate, their social resources (Bayer \& Hofstra, 2020).

\section{Downstream outcomes}

How people mentally organize their various friends, families, and acquaintances may influence a wide range of outcomes of interest to psychologists (Bacev-Giles \& Peetz, 2016). In other words, dynamic network cognition may have effects well beyond discrete mobilization goals (e.g., obtaining advice from other people). Oftentimes, an everyday task does not call to mind a person so much as a shortlist ("Who could I reach out to?"). Such mental shortlists-and the perceived structure therein-may affect subjective perceptions of social support (Lee, Stahl, \& Bayer, in press), influence the expressions of stereotypes (Smith et al., 2020), or carry over to subsequent social interactions (Bayer, Hauser, Shah, O’Donnell, \& Falk, 2019). Perhaps most notably, although past research has identified links between individual differences (e.g., extraversion, selfmonitoring) and objective network structure (Brands, 20l3), the cognitive mechanisms underlying actual network changes are poorly understood.

Given these possible outcomes, future studies should test how activation occurs across diverse contexts as well as how the embedded networks contribute to social resources (e.g., perceived support vs. loneliness), social behavior (e.g., in-group vs. out-group interactions), and social environments (e.g., heterogeneous vs. homogenous friends). At the same time, researchers must con- sider how these mechanisms - and aforementioned technologies-have downstream implications for social disparities (e.g., the "boys-club" phenomenon). On one hand, online network tools offer some potential for connecting populations with disparities to advancement opportunities (e.g., Jeon, Ellison, Hogan, \& Greenhow, 2016). As with all new technologies, though, there is also the potential for them to further exaggerate inequalities. In sum, future work should examine how activated networks shape in vivo social cognition and ensuing social outcomes as a network-based form of situated cognition.

\section{Conclusion}

What remains missing from the current research landscape is an integrated view on socialnetwork activation and how these dynamic mechanisms occur across daily life. We contend that psychological researchers must clarify whether these momentary networks matter to a wider variety of contexts and consequences - especially given the potential of online technologies to 
spontaneously impact who comes to mind. Consequently, researchers, designers, and policymakers should investigate how social-network activation affects everyday behavior, along with the individual opportunities and societal risks that come built in.

\section{References}

Anthony, A. K., \& McCabe, J. (2015). Friendship talk as identity work: Defining the self through friend relationships. Symbolic Interaction, 38, 64-82. doi:10.1002/symb. 138

Bacev-Giles, C., \& Peetz, J. (2016). Thinking big or small: Does mental abstraction affect social network organization? PLOS ONE, I I(I), Article e0160047. doi:I0.137I/ journal.pone.0147325

Bayer, J. B., Campbell, S. W., \& Ling, R. (2016). Connection cues: Activating the norms and habits of social connectedness. Communication Theory, 26, 128-149. doi: I0.I I I I/ comt. 12090

Bayer, J. B., Hauser, D. J., Shah, K. M., O’Donnell, M. B., \& Falk, E. B. (2019). Social exclusion shifts personal network scope. Frontiers in Psychology, 10, Article 1619. doi:10.3389/fpsyg.2019.01619

Bayer, J. B., \& Hofstra, B. (2020). Toward curation and personality-driven social networks. Nature Human Behaviour, 4, 123-125.

Bernard, H. R., \& Killworth, P. D. (1977). Informant accuracy in social network data II. Human Community Research, 4, 3-18. doi:I0.1 I I I/j.I468-2958.1977.tb0059I.x

Brands, R. A. (2013). Cognitive social structures in social network research: A review. Journal of Organizational Behavior, 34, S82-S103. doi:10.1002/job.1890

Brashears, M. E. (20I3). Humans use compression heuristics to improve the recall of social networks. Scientific Reports, 3, Article 15I3. doi:10.1038/srep01513

Brashears, M. E., Hoagland, E., \& Quintane, E. (2016). Sex and network recall accuracy. Social Networks, 44, 74-84. doi:10.1016/j.socnet.2015.06.002

Brashears, M. E., \& Quintane, E. (2015). The microstructures of network recall: How social networks are encoded and represented in human memory. Social Networks, 4I, II3-I26. doi:10.1016/j.socnet.2014.11.003

Burt, R. S., Jannotta, J. E., \& Mahoney, J. T. (1998). Personality correlates of structural holes. Social Networks, 20, 63-87. doi:I0.I0I6/S0378-8733(97)00005-I

Burt, R. S., Kilduff, M., \& Tasselli, S. (2013). Social network analysis: Foundations and frontiers on advantage. Annual Review of Psychology, 64, 527-547. doi: I 0.I I46/annurev- psych-I I 30 I I-I 43828

Casciaro, T., Barsade, S. G., Edmondson, A. C., Gibson, C. B., Krackhardt, D., \& Labianca, G. (20I5). The integration of psychological and network perspectives in organizational scholarship. Organization Science, 26, II62-1176.

Dunbar, R. I. M. (20I8). The anatomy of friendship. Trends in Cognitive Sciences, 22, 32-5I. doi:10.1016/j.tics.2017 .10.004

Fitzsimons, G. M., \& Bargh, J. A. (2003). Thinking of you: Nonconscious pursuit of interpersonal goals associated with relationship partners. Journal of Personality and Social Psychology, 84, I48-164.

Fitzsimons, G. M., \& Finkel, E. J. (2018). Transactive-goal-dynamics theory: A discipline-wide perspective. Current Directions in Psychological Science, 27, 332-338. doi:I0.1 I77/096372। 4 I7754I 99

Flynn, F. J., Reagans, R. E., \& Guillory, L. (2010). Do you two know each other? Transitivity, homophily, and the need for (network) closure. Journal of Personality and Social Psychology, 99, 855-869. doi: I0.1037/a002096 I

Honeycutt, J. M., Vickery, A. J., \& Hatcher, L. C. (2015). The daily use of imagined interaction features. Communication Monographs, 82, 20I-223.

Igarashi, T., \& Kashima, Y. (20I I). Perceived entitativity of social networks. Journal of Experimental Social Psychology, 47, 1048-1058. doi:I0.1016/j.jesp.20II.04.008 
Jeon, G. Y., Ellison, N. B., Hogan, B., \& Greenhow, C. (2016). First-generation students and college: The role of Facebook networks as information sources. In CSCW' 16: Proceedings of the 19th ACM Conference on Computer-Supported Cooperative Work \& Social Computing (pp. 887-899). New York, NY: Association for Computing Machinery. doi: 10 .I I 45/28I8048.2820074

Kilduff, M., Crossland, C., Tsai, W., \& Krackhardt, D. (2008). Organizational network perceptions versus reality: A small world after all? Organizational Behavior and Human Decision Processes, 107, 15-28. doi:10.1016/j .obhdp.2007.12.003

Kilduff, M., \& Lee, J. W. (2020). The integration of people and networks. Annual Review of Organizational Psychology and Organizational Behavior, 7(I), I55-I79.

Kobayashi, T., Boase, J., Suzuki, T., \& Suzuki, T. (2015). Emerging from the cocoon? Revisiting the telecocooning hypothesis in the smartphone era. Journal of Computer-Mediated Communication, 20, 330345. doi: $10.1111 /$ jcc4.12116

Krackhardt, D. (1987). Cognitive social structures. Social Networks, 9, 109-134. doi:10.1016/03788733(87)90009-8

Lee, D. S., Stahl, J. S., \& Bayer, J. B. (in press). Social resources as cognitive structures: Thinking about a dense support network increases perceived support. Social Psychology Quarterly.

Litt, E. (2012). Knock, knock. Who's there? The imagined audience. Journal of Broadcasting and Electronic Media, 56, 330-345. doi:10.1080/08838I5I.20I2.705I95

Marin, A. (2004). Are respondents more likely to list alters with certain characteristics? Implications for name generator data. Social Networks, 26, 289-307. doi:10.1016/j.socnet.2004.06.00 I

Mattan, B. D., Kubota, J. T., \& Cloutier, J. (2017). How social status shapes person perception and evaluation: A social neuroscience perspective. Perspectives on Psychological Science, 12, 468-507. doi:10.1I77/I74569/616677828

Menon, T., \& Smith, E. B. (2014). Identities in flux: Cognitive network activation in times of change. Social Science Research, 45, I17-130. doi:10.1016/j.ssresearch.2014.01.001

Orahek, E., \& Forest, A. L. (2016). When people serve as means to goals: Implications of a motivational account of close relationships. Current Directions in Psychological Science, 25, 79-84.

Oyserman, D., \& Lewis, N. A., Jr. (2017). Seeing the destination AND the path: Using identity-based motivation to understand and reduce racial disparities in academic achievement. Social Issues and Policy Review, II, I59- I94. doi: I0.I I I I/sipr. I 2030

Oyserman, D., Lewis, N. A., Jr., Yan, V. X., Fisher, O., O’Donnell, S. C., \& Horowitz, E. (2017). An identity-based motivation framework for self-regulation. Psychological Inquiry, 28, I39-147. doi: 10.1080/1047840X.2017.1337406

Raj, M., Fast, N. J., \& Fisher, O. (2017). Identity and professional networking. Personality and Social Psychology Bulletin, 43, 772-784. doi:I0.1 I77/0I461672I7697299

Shea, C. T., \& Fitzsimons, G. M. (2016). Personal goal pursuit as an antecedent to social network structure. Organizational Behavior and Human Decision Processes, 137, 45-57. doi:10.1016/j.obhdp.2016.07.002

Shea, C. T., Menon, T., Smith, E. B., \& Emich, K. (20I5). The affective antecedents of cognitive social network activation. Social Networks, 43, 9I-99. doi:10.1016/j.socnet.2015.01.003

Small, M. L. (2009). Unanticipated gains: Origins of network inequality in everyday life. New York, NY: Oxford University Press.

Small, M. L. (2017). Someone to talk to. Oxford, England: Oxford University Press. doi:I0.1093/oso/9780I9066I427.00I.000I Small, M. L., \& Sukhu, C. (20I6). Because they were there: Access, deliberation, and the mobilization of networks for support. Social Networks, 47, 73 84. doi:10.1016/j.socnet.2016.05.002

Smith, E. B., Brands, R. A., Brashears, M. E., \& Kleinbaum, A. M.(2020). Social networks and cognition. Annual Review of Sociology. Advance online publication. doi:I0.I I46/ annurev-soc-I2 I919-054736 
Smith, E. B., Menon, T., \& Thompson, L. (2012). Status differences in the cognitive activation of social networks. Organization Science, 23, 67-82.

Sutcliffe, A., Dunbar, R., Binder, J., \& Arrow, H. (20I2). Relationships and the social brain: Integrating psychological and evolutionary perspectives. British Journal of Psychology, 103, I49-168.

Walker, M. H., \& Lynn, F. B. (2013). The embedded self : A social networks approach to identity theory. Social Psychology Quarterly, 76, I5I-179. doi:10.II77/0190272513482929

Wentura, D., \& Rothermund, K. (20I4). Priming is not priming is not priming. Social Cognition, 32, 47-67. doi: I0.152I/ soco.20I4.32.supp.47

Westaby, J. D., Pfaff, D. L., \& Redding, N. (20I4). Psychology and social networks: A dynamic network theory perspective. American Psychologist, 69, 269-284.

Wood, W. (2017). Habit in personality and social psychology. Personality and Social Psychology Review, 21 , 389-403. doi: I0.1 I77/10888683 I7720362

Zitek, E. M., \& Tiedens, L. Z. (20I2). The fluency of social hierarchy: The ease with which hierarchical relationships are seen, remembered, learned, and liked. Journal of Personality and Social Psychology, 102, 98-II5. doi:10 .1037/a0025345

\section{Recommended Reading}

- Brands, R. A. (20I3). (See References).

- A clearly written overview of past research on cognitive social networks.

- Brashears, M. E., \& Quintane, E. (20I5). (See References).

- A representative study on the fundamental mechanisms of socialnetwork cognition.

- Burt, R. S., Kilduff, M., \& Tasselli, S. (20I3). (See References).

- A pivotal review and call for research on the psychological foundations of social networks.

- Clifton, A., \& Webster, G. D. (2017). An introduction to social network analysis for personality and social psychologists. Social Psychological and Personality Science, 8, 442-453.

- A useful primer for psychologists interested in adopting socialnetwork methods.

- Falk, E. B., \& Bassett, D. S. (2017). Brain and social networks: Fundamental building blocks of human experience. Trends in Cognitive Sciences, 21 , 674-690.

- An integrative review of the links between social networks and neuro-cognitive processes.

- Kilduff, M., \& Lee, J. W. (2020). (See References).

- An authoritative summary of past perspectives and future directions tied to the psychology of social networks. 